\title{
MODELOWANIE OŚRODKA LEPKOSPRĘŻYSTEGO W METODZIE ELEMENTÓW CZASOPRZESTRZENNYCH
}

\begin{abstract}
W pracy rozpatruje się ośrodek lepkosprężysty, który został opisany równaniami całkowymi (model całkowy) z wykorzystaniem funkcji relaksacji (tensorowej funkcji relaksacji). Opracowano model obliczeniowy do analizy takich ośrodków $\mathrm{z}$ użyciem metody elementów czasoprzestrzennych. Zamieszczony przykład obliczeń (tarcza lepkosprężysta) wskazuje na poprawność i efektywność tego modelu obliczeniowego.
\end{abstract}

Słowa kluczowe: ośrodek lepkosprężysty, metoda elementów czasoprzestrzennych, model obliczeniowy

\section{Wstęp}

Nowatorskim wariantem metody elementów skończonych (MES) jest metoda elementów czasoprzestrzennych (MECZ), której podstawy stworzył w latach 70. XX wieku Profesor Kączkowski [4,5]. Cechą wyróżniającą MECZ od innych metod bezpośredniego całkowania równań ruchu jest charakterystyczna aproksymacja funkcji czasoprzestrzennych (w przypadku mechaniki ciała stałego: pól przemieszczeń, odkształceń, naprężeń i innych funkcji) w całym analizowanym obszarze czasoprzestrzennym.

Problemy związane z wyznaczaniem naprężeń i odkształceń w ciałach lepkosprężystych komplikują się głównie z powodu równań fizycznych, które występują w postaci dość złożonych równań różniczkowych lub całkowych [3,9].

Wydaje się, że metoda elementów czasoprzestrzennych stwarza nową jakość, zwłaszcza w niestacjonarnych zagadnieniach początkowo-brzegowych. Odnosi się to także do ośrodka lepkosprężystego. W niniejszej pracy pokazano modelowanie dowolnego ośrodka lepkosprężystego w metodzie elementów czasoprzestrzennych.

\footnotetext{
${ }^{1}$ Magdalena Lachowicz, Uniwersytet Technologiczno-Przyrodniczy im. J. J. Śniadeckich, Wydział Budownictwa, Architektury i Inżynierii Środowiska, ul. Al. prof. S. Kaliskiego 7, 85-796 Bydgoszcz, 523408500,m.lachowicz@utp.edu.pl
} 


\section{Problem początkowo-brzegowy ośrodka lepko-sprężystego}

Rozpatruje się ośrodek lepkosprężysty zajmujący obszar $\bar{V}$, który jest podzbiorem przestrzeni euklidesowej trójwymiarowej $R^{3}$. Przez $V$ oznacza się wnętrze tego obszaru, a przez $\partial V$ jego brzeg, który jest sumą zbiorów $\partial V_{t}$ i $\partial V_{u}$ (na powierzchni $\partial V_{t}$ znane są obciążenia, a na $\partial V_{u}$ przemieszczenia).

Ruch ciała analizuje się $\mathrm{w}$ przedziale $t \in\langle 0, \infty)$. Ciało to podlega infinitezymalnym deformacjom, co oznacza ośrodek geometrycznie liniowy. Zmienne dynamiczne składające się z pola wektorowego przemieszczeń $\boldsymbol{u}$ i sił masowych $\varrho \boldsymbol{f}$, symetrycznego pola tensorowego naprężeń $\boldsymbol{\sigma}$ i odkształceń $\boldsymbol{\varepsilon}$ określone są na iloczynie kartezjańskim zbiorów $(\boldsymbol{X}, t) \in V \times\langle 0, \infty)$. Pole wektorowe obciążeń powierzchniowych $\hat{\boldsymbol{t}}$ opisane jest natomiast na iloczynie $(\boldsymbol{X}, t) \in \partial V_{t} \times\langle 0, \infty)$. Wymienione zmienne dynamiczne są funkcjami ciągłymi i dostatecznie gładkimi. Dany jest obszar $\left(V, \partial V_{t} i \partial V_{u}\right)$ z warunkami brzegowymi, obciążenie powierzchniowe $\hat{\boldsymbol{t}}(\boldsymbol{X}, t)$ i masowe $\varrho \boldsymbol{f}$, funkcje relaksacji $\boldsymbol{\Psi}$ oraz warunki początkowe.

Poszukuje się pola przemieszczenia $u_{i}(\boldsymbol{X}, t)$, odkształcenia $\varepsilon_{i j}(\boldsymbol{X}, t)$ i naprężenia $\sigma_{i j}(\boldsymbol{X}, t)(i, j=1,2,3)$.

Przedstawiony problem (materiał liniowo lepkosprężysty) można opisać następującym zestawem równań $[2,3,8]$ :

$$
\begin{aligned}
& \frac{\partial \sigma_{i j}}{\partial X_{i}}+\varrho f_{j}=\varrho \ddot{u}_{j} \\
& \varepsilon_{i j}=\frac{1}{2}\left(\frac{\partial u_{i}}{\partial X_{j}}+\frac{\partial u_{j}}{\partial X_{i}}\right) \\
& \sigma_{i j}=\Psi_{i j k l}(\boldsymbol{X}, 0) \varepsilon_{k l}(\boldsymbol{X}, t)+\int_{0}^{t} \varepsilon_{k l}(\boldsymbol{X}, t-\tau) \dot{\Psi}_{i j k l}(\boldsymbol{X}, \tau) d \tau ; \\
& (\boldsymbol{X}, t) \in V \times\langle 0, \infty\rangle
\end{aligned}
$$

Uzupełnieniem są warunki brzegowe:

$$
\begin{aligned}
& \hat{t}_{j}=\sigma_{i j} n_{i} ;(\boldsymbol{X}, t) \in \partial V_{p} \times\langle 0, \infty) ; \\
& u_{j}=\hat{u}_{j} ;(\boldsymbol{X}, t) \in \partial V_{u} \times\langle 0, \infty)
\end{aligned}
$$

i warunki początkowe:

$$
u_{j}=u_{j}^{0} ; \dot{u}_{j}=\vartheta_{j}^{0} ;(\boldsymbol{X}, t) \in V \times\{0\}
$$

Wielkość $\Psi_{i j k l}\left(X, 0^{+}\right)$jest wartością graniczną $\Psi_{i j k l}(X, t)$, gdy $t \rightarrow 0$ od strony dodatniej. Wielkość $\Psi_{i j k l}$ jest polem tensorowym czwartego rzędu, nazywanym 
tensorową funkcją relaksacji. Symetria tensorów naprężenia $\sigma_{i j}$ i odkształcenia $\varepsilon_{i j}$ powoduje symetrię tensora $\Psi_{i j k l}$, tzn.

$$
\Psi_{i j k l}=\Psi_{j i k l}=\Psi_{i j l k}
$$

Jeżeli tensor $\Psi_{i j k l}$ jest niezmienniczy względem obrotu osi współrzędnych, wtedy mamy do czynienia z materiałem izotropowym i wówczas

$$
\Psi_{i j k l}=\frac{\Psi_{2}-\Psi_{1}}{3} \delta_{i j} \delta_{k l}+\frac{\Psi_{1}}{2}\left(\delta_{i k} \delta_{j l}+\delta_{i l} \delta_{j k}\right)
$$

Funkcje $\Psi_{1}$ i $\Psi_{2}$ nazywane są funkcjami relaksacyjnymi odpowiadającymi kolejno ścinaniu (zmiana postaci) i wszechstronnemu ściskaniu (zmiana objętości). W dalszych rozważaniach przyjmujemy, że funkcje tworzące $\Psi_{i j k l}$ wyznaczane są doświadczalnie.

Na bazie równań $(1)_{1}$ i $(2)_{1}$ można wyprowadzić równanie czasopracy wirtualnej $[6,9]$ :

$$
\begin{aligned}
& \int_{0}^{t_{1}}\left[\int_{V} \varrho\left(f_{j} \delta u_{j}+\dot{u}_{j} \delta \dot{u}_{j}\right) d V+\int_{\partial V_{t}} \hat{t}_{j} \delta u_{j} d(\partial V)\right] d t= \\
& =\int_{0}^{t_{1}} \int_{V} \delta \varepsilon_{i j} \sigma_{i j} d V d t
\end{aligned}
$$

gdzie $\delta u_{j}$ i $\delta \varepsilon_{i j}$ oznaczają wariację kolejno przemieszczeń i odkształceń. Poszczególne całki równania (6) wyrażone są w $J \cdot s=N \cdot m \cdot s$, dlatego to równanie nazywa się równaniem czasopracy lub czasoenergii. Równanie (6) to w istocie zasada Hamiltona $[1,2,10]$.

\section{Równania MECZ}

Dyskretyzacja obszaru czasoprzestrzennego odbywa się w sposób charakterystyczny dla MES. Dotyczy to także dyskretyzacji po współrzędnej czasowej (rys. 1.). Istnieje tutaj duża dowolność i możliwość dostosowania dyskretyzacji do analizowanego zjawiska, procesu.

Poszczególne parametry lepkosprężyste $\Psi_{i j k l}$ wyrażone są w postaci funkcji relaksacji (rys. 2a). Funkcje te można zdyskretyzować w sposób dostosowany do zdyskretyzowanego pasma czasoprzestrzennego (rys. 2b). Przyjmuje się, że w obszarze skończonego elementu czasoprzestrzennego (SKECZ) zmienność funkcji $\Psi_{i j k l}$ jest liniowa. Jest to w pełni uzasadnione biorąc pod uwagę mały wymiar czasowy SKECZ [7]. 

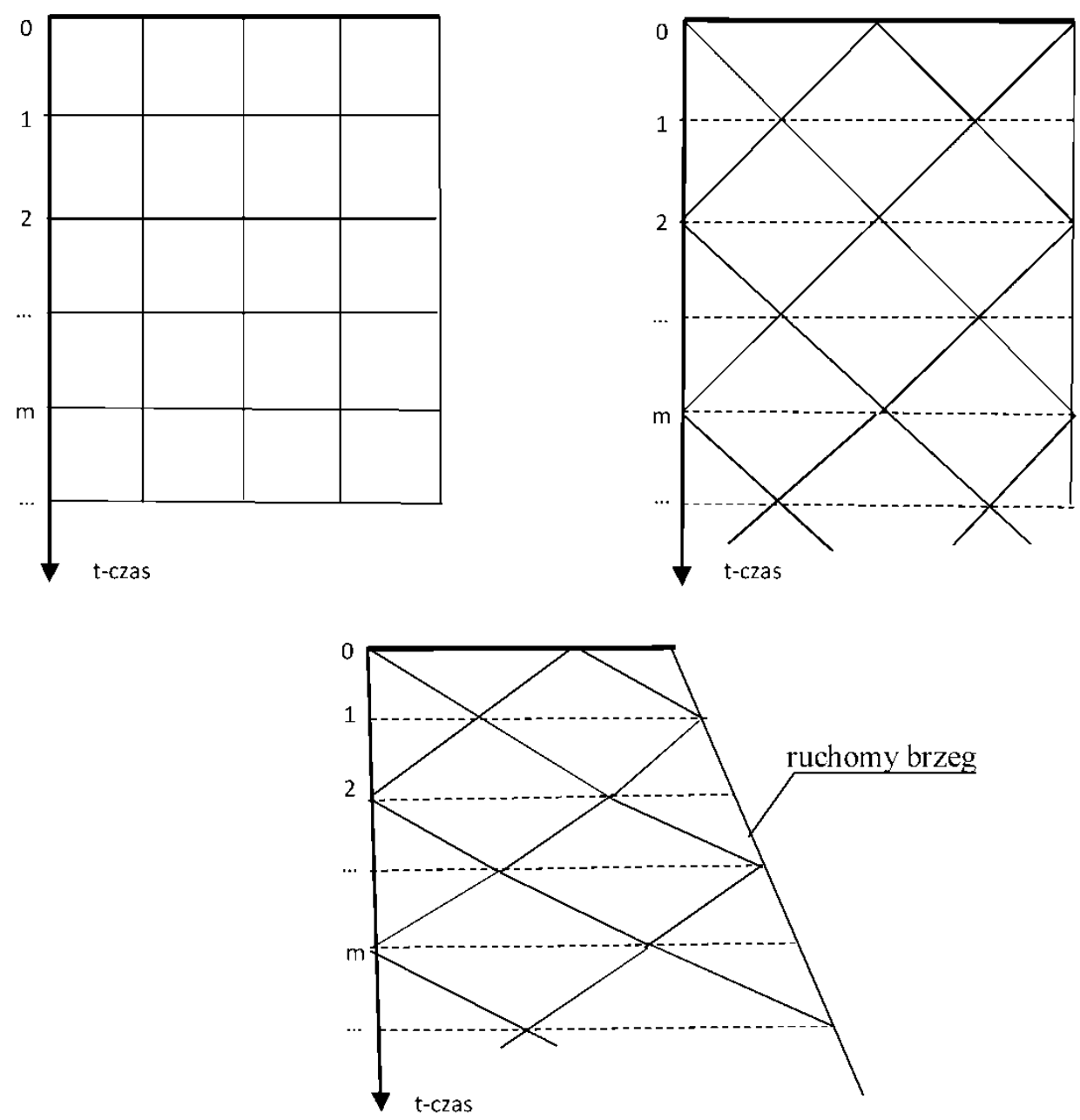

Rys. 1. Przykłady dyskretyzacji obszaru czasoprzestrzennego po współrzędnej czasowej $t$

Fig. 1. Examples of space time discretization along time coordinate $t$

Na podstawie równania czasopracy wirtualnej (6), trzymając się zasad charakterystycznych dla MES, otrzymuje się następujący układ równań algebraicznych MECZ $[4,5,9]$

$$
\Lambda=K r+F=0
$$

w którym $\boldsymbol{K}$ jest globalną macierzą sztywności czasoprzestrzennej, a $\boldsymbol{r}$ i $\boldsymbol{F}$ są wektorami poszukiwanych przemieszczeń węzłowych i znanych impulsów wywołujących ruch. Elementy macierzy $\boldsymbol{K}$ opisane są następującym wzorem [7]. 

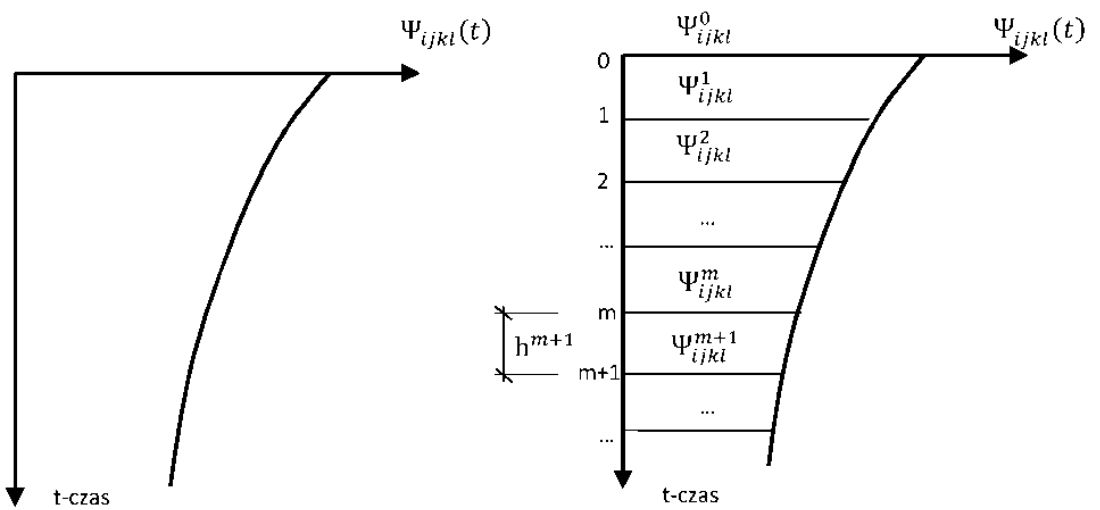

Rys. 2. Funkcja relaksacji (a) z odpowiednią dyskretyzacją (b)

Fig. 2. Function of relaxation (a) with appropriate discretization (b)

$$
K_{\alpha \beta}^{e m}=\iint_{\Omega_{e}}\left(B_{i j \alpha}^{e} C_{i j \beta}^{e m}-\dot{\Phi}_{j \alpha}^{e} \varrho^{e} \dot{\Phi}_{j \beta}^{e}\right) d \Omega
$$

gdzie:

$$
\begin{aligned}
C_{i j \beta}^{e m} & =\Psi_{i j k l}^{e m}\left(\boldsymbol{X},-t_{p}^{e}\right) B_{k l \beta}^{e}(\boldsymbol{X}, t)+A_{i j k l}^{e m} \int_{-t_{p}^{e}}^{t_{k}^{e}} B_{k l \beta}^{e}(\boldsymbol{X}, t-\tau) d \tau \\
A_{i j k l}^{e m} & =\frac{\Psi_{i j k l}^{e, m+1}-\Psi_{i j k l}^{e m}}{h^{e, m+1}}
\end{aligned}
$$

Inne oznaczenia:

$\Phi_{i \alpha}^{e}=\Phi_{i \alpha}^{e}(\boldsymbol{X}, t)-$ funkcja kształtu;

$\Omega_{e}$-obszar SKECZ, $i, j, k, l=1,2,3$;

$\alpha, \beta=1,2,3, \ldots, w_{e} \cdot s_{e}\left(w_{e}-\right.$ liczba węzłów SKECZ, $s_{e}-$ liczba stopni swobody w węźle SKECZ);

$e=1,2, \ldots, E$ ( $E-$ liczba SKECZ), $m=0,1,2, \ldots$ (rys. $1-2)$.

Dopełnieniem do użytych oznaczeń jest rys. 3. 


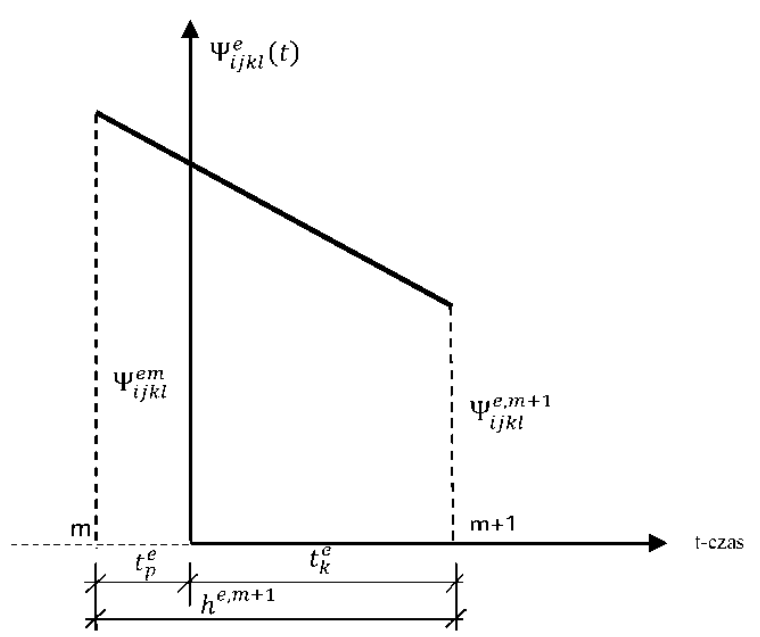

Rys. 3. Opis funkcji relaksacji $\Psi_{k l m}^{e}(t)$ w obszarze SKECZ, w układzie współrzędnych lokalnych Fig. 3. Description of function of relaxation $\Psi_{k l m}^{e}(t)$ in FSTE area, in the system of local coordinates

Przy znanych warunkach początkowych, równania MECZ (7) przekształcają się w schemat rekurencyjny w postaci [np. 5, 9]:

$$
\begin{aligned}
& \boldsymbol{r}^{1}=\left(\boldsymbol{B}^{0}\right)^{-1}\left(-\boldsymbol{F}^{0}-\boldsymbol{A}^{0} \boldsymbol{r}^{0}\right) \\
& \boldsymbol{r}^{2}=\left(\boldsymbol{B}^{1}\right)^{-1}\left[-\boldsymbol{F}^{1}-\boldsymbol{C}^{1} \boldsymbol{r}^{0}-\left(\boldsymbol{D}^{1}+\boldsymbol{A}^{1}\right) \boldsymbol{r}^{1}\right] \\
& \boldsymbol{r}^{m+1}=\left(\boldsymbol{B}^{m}\right)^{-1}\left[-\boldsymbol{F}^{m}-\boldsymbol{C}^{m} \boldsymbol{r}^{m-1}-\left(\boldsymbol{D}^{m}+\boldsymbol{A}^{m}\right) \boldsymbol{r}^{m}\right]
\end{aligned}
$$

Macierze $\boldsymbol{A}^{m}, \boldsymbol{B}^{m}, \boldsymbol{C}^{m}$ i $\boldsymbol{D}^{m}$ są podmacierzami macierzy globalnej $\boldsymbol{K}$ sformułowanymi w chwili $m=0,1,2, \ldots$ (por. rys. 1-2) [np. 5, 7, 9].

\section{Przykład obliczeń} (rys. 4.)

Rozpatruje się tarczę lepkosprężystą poddaną obciążeniu poprzecznemu

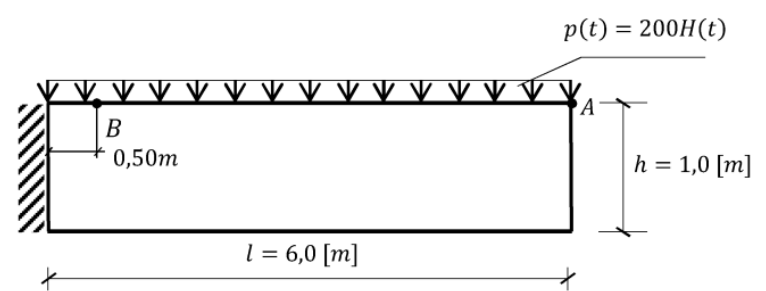

Rys. 4. Analizowana tarcza lepkosprężysta

Fig. 4. Analyzed viscous elastic disc

$H(t)$ - funkcja Heaviside'a

$t=0,20[\mathrm{~m}]-$ grubość tarczy; $\varrho=7800\left[\frac{\mathrm{kg}}{\mathrm{m}^{3}}\right] ; E=2,1 \cdot 10^{11}\left[\frac{\mathrm{N}}{\mathrm{m}^{2}}\right]$

$v=0,3$

$h^{e}=1,0 \cdot 10^{-4}[s]-$ wymiar czasowy SKECZ 
Przyjęto, że materiał tarczy jest jednorodny i izotropowy. Ponadto przyjęto, że zmiana postaci ma charakter lepkosprężysty, o przykładowej funkcji relaksacji:

$$
\begin{aligned}
& \Psi_{1}(t)=\mu\left(1+e^{-\varkappa t}\right) \\
& \mu=G=\frac{E}{2(1+v)}
\end{aligned}
$$

a zmiana objętości zachodzi sprężyście:

$$
\begin{aligned}
& \Psi_{2}(t)=3 K \\
& K=\frac{E}{2(1+v)}
\end{aligned}
$$

Wielkość $\mathcal{\varkappa}$ jest parametrem opisującym intensywność relaksacji, w przypadku $\varkappa=0,0$ mamy do czynienia $\mathrm{z}$ ośrodkiem sprężystym.

Poniżej przedstawia się wykresy przemieszczeń pionowych punktu $A$ w zależności od wartości parametru $\mathcal{\varkappa}$ (rys. 5-6) oraz naprężeń normalnych w punkcie $B$ (rys. 7.).

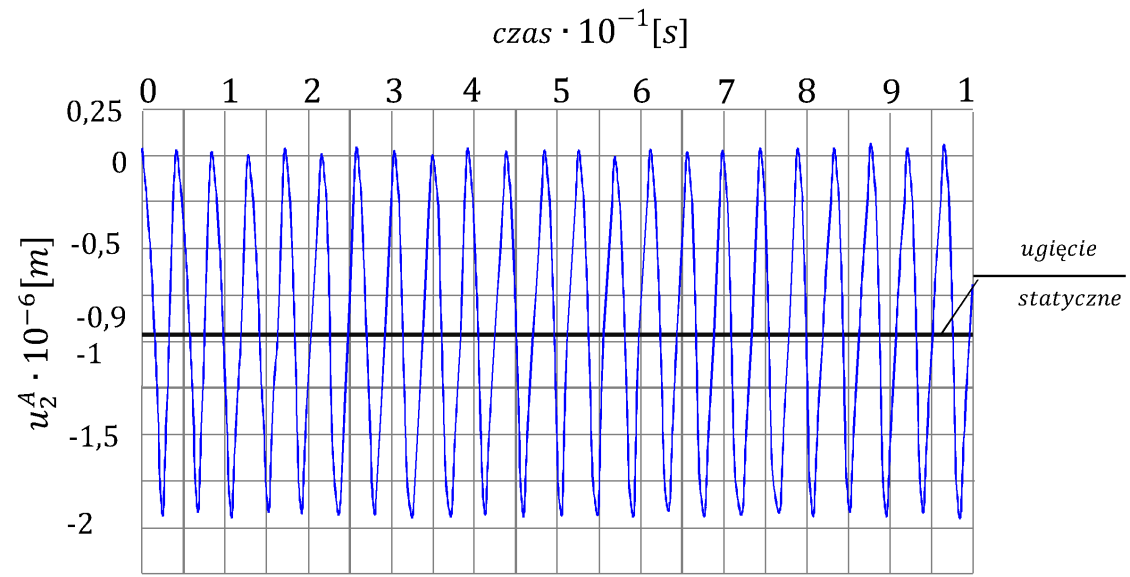

Rys. 5. Tarcza sprężysta: $\Psi_{1}=2 \mu, \Psi_{2}=3 \mathrm{~K}$. Przemieszczenie pionowe punktu A, u $\mathrm{u}_{2}^{\mathrm{A}}$ - ugięcie od statycznego działania obciążenia (wspornik) - ugięcie tarczy od dynamicznego działania obciążenia

Fig. 5. Elastic disc : $\Psi_{1}=2 \mu, \Psi_{2}=3 \mathrm{~K}$. Vertical displacement of point $\mathrm{A}, \mathrm{u}_{2}^{\mathrm{A}}$ - deflection caused in effect of static load (support) - deflection of disc caused in effect of dynamic load 


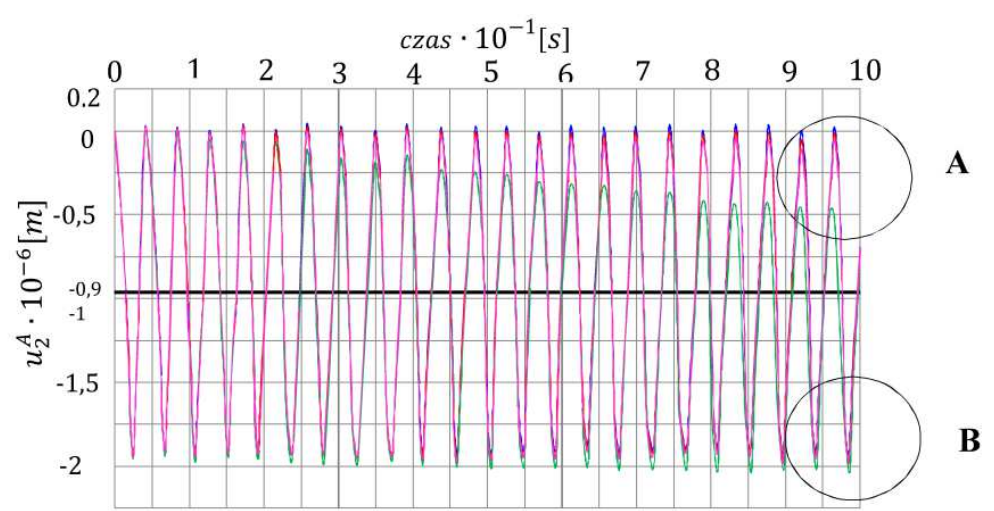

A

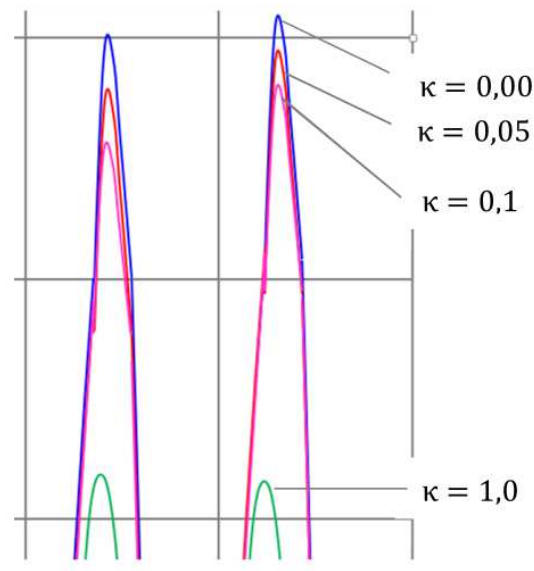

B

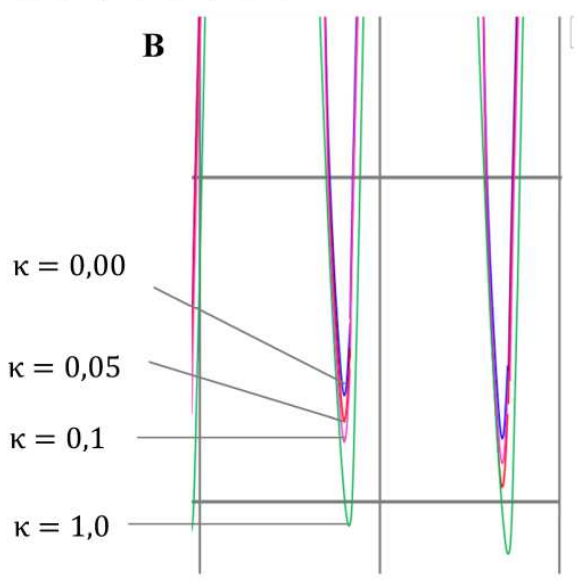

Rys. 6. Tarcza lepkosprężysta: $\Psi_{1}(\mathrm{t})=\mu\left(1+\mathrm{e}^{-\kappa \mathrm{t}}\right), \kappa=0,0 ; \kappa=0,05 ; \kappa=0,1 ; \kappa=1,0 ; \Psi_{2}=3 \mathrm{~K}$.

Przemieszczenie pionowe $w$ punkcie $A, u_{2}^{A}$

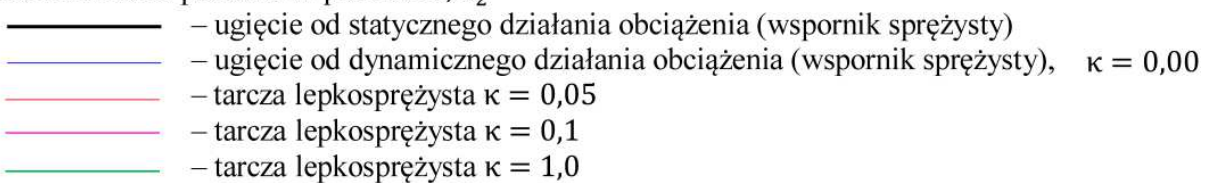

Fig. 6. Viscous elastic disc: $\Psi_{1}(\mathrm{t})=\mu\left(1+\mathrm{e}^{-\kappa \mathrm{t}}\right), \kappa=0,0 ; \kappa=0,05 ; \kappa=0,1 ; \kappa=1,0 ; \Psi_{2}=3 \mathrm{~K}$. Vertical displacement in point $\mathrm{A}, \mathrm{u}_{2}^{\mathrm{A}}$

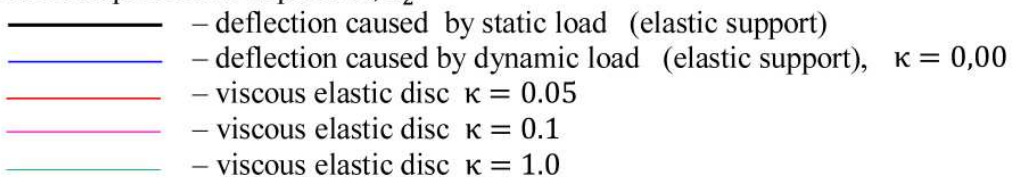




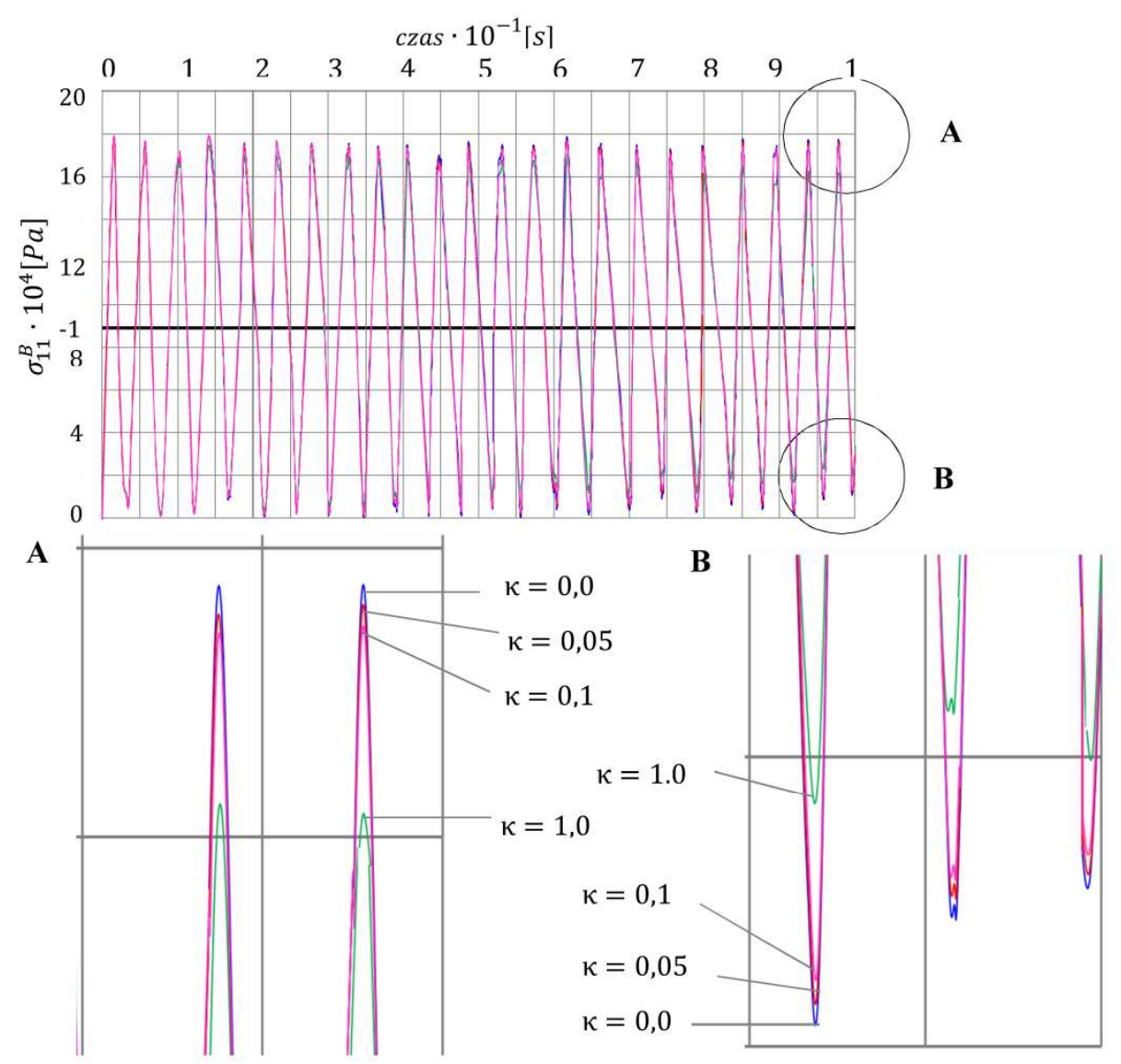

Rys. 7. Tarcza lepkosprężysta: $\Psi_{1}(\mathrm{t})=\mu\left(1+\mathrm{e}^{-\kappa \mathrm{t}}\right), \kappa=0,0 ; \kappa=0,05 ; \kappa=0,1 ; \kappa=1,0$;

$\Psi_{2}=3 \mathrm{~K}$. Naprężenia normalne w punkcie $\mathrm{B}, \sigma_{11}^{\mathrm{B}}$

- naprężenia od statycznego działania siły (wspornik sprężysty)

- naprężenia od dynamicznego działania siły (wspornik sprężysty), $\quad \kappa=0,00$

- tarcza lepkosprężysta, $\kappa=0,05$

- tarcza lepkosprężysta, $\kappa=0,1$

- tarcza lepkosprężysta, $\kappa=1,0$

Fig. 7. Viscous elastic disc : $\Psi_{1}(\mathrm{t})=\mu\left(1+\mathrm{e}^{-\kappa \mathrm{t}}\right), \kappa=0,05 ; \kappa=.1 ; \kappa=1,0 ; \Psi_{2}=3 \mathrm{~K}$. Normal stress in point $\mathrm{B}, \sigma_{11}^{\mathrm{B}}$

- - stresses caused by static force (elastic support )

- stresses caused by dynamic force (elastic support), $\quad \kappa=0,00$

- viscous elastic disc, $\kappa=0.05$

- viscous elastic disc, $\kappa=0.1$

- viscous disc, $\kappa=1.0$ 
Rozważana tarcza jest $w$ istocie zginanym wspornikiem. Stosując inżynierską teorię belkową, dysponujemy następującym znanym rozwiązaniem od statycznego obciążenia $p(t)=p_{0}=200 \mathrm{kN} / \mathrm{m}$ (ugięcie końca wspornika sprężystego):

- bez uwzględnienia ścinania $-w_{\max }=9,26 \cdot 10^{-6} \mathrm{~m}$;

- $\mathrm{z}$ uwzględnieniem ścinania $-w_{\max }=9,52 \cdot 10^{-6} \mathrm{~m}$.

Można też wyznaczyć dla wspornika sprężystego częstotliwość drgań własnych, ze znanego wzoru, np. dwie pierwsze częstotliwości:

$\omega_{1}=146,23 \mathrm{~Hz} ; \omega_{2}=916,75 \mathrm{~Hz}$.

Otrzymane wyniki obliczeń numerycznych MECZ wskazują na wysoką zgodność i poprawność jakościową zastosowanego modelu lepkosprężystego, ponieważ:

- Amplituda ugięcia tarczy sprężystej w punkcie $A, u_{2}^{A}$ mieści się w przedziale $1,83 \cdot 10^{-6} \div 1,91 \cdot 10^{-6} \mathrm{~m}$, wobec ugięcia statycznego wynoszącego 9,3 . $10^{-6} \div 9,5 \cdot 10^{-6} \mathrm{~m}$. Oznacza to, że amplituda ugięcia wynosi prawie $2 u_{\text {stat. }}$. Wysoka zgodność wyników obliczeń dotyczy także częstotliwości drgań.

- Ze wzrostem parametru $\varkappa$ charakteryzującym intensywność relaksacji stwierdzono m.in.:

- spadek amplitudy przemieszczeń, jest to efekt tłumienia drgań (rys. 6.),

- spadek amplitudy naprężeń, jest to efekt relaksacji.

$\mathrm{W}$ podsumowaniu należy zaznaczyć, że stwierdzono w przedstawionym przykładzie obliczeń takie charakterystyczne i oczekiwane efekty jak:

- tłumienie drgań,

- pełzanie (przyrost odkształceń w czasie),

- relaksacja (spadek naprężeń w czasie).

Efektywność tych zjawisk zależy oczywiście od udziału fazy lepkiej w odniesieniu do fazy sprężystej, czyli od przyjętej funkcji relaksacji.

\section{Podsumowanie}

Do opisu lepkosprężystych cech materiałów konstrukcyjnych przyjęto model całkowy. Związki fizyczne opisano z wykorzystaniem funkcji relaksacji. Funkcje te można wyznaczyć doświadczalnie, co umożliwia uwzględnienie jednocześnie zjawisk różnego typu nieciągłości, efektów starzenia itp. Biorąc pod uwagę specyficzne cechy MECZ (np. mały wymiar czasowy SKECZ) opracowano sposób (model) zdefiniowania naprężeń w obszarze SKECZ. Jest to oryginalny element pracy.

Wykazano, że modelowanie ośrodka lepkosprężystego nie zaburza ogólnego algorytmu obliczeń metodą elementów czasoprzestrzennych. Przy znanych warunkach początkowych, równania MECZ sprowadzają się do formuły rekurencyjnej.

W profesjonalnych programach komputerowych, w których rozwiązuje się przeróżne problemy początkowo-brzegowe (np. ABAQUS, ANSYS) stosuje się 
rozprzężenie przestrzeni od czasu. W związku z tym można zauważyć, że przy większych prędkościach analizowanych zjawisk to rozprzężenie może być źródłem znacznych niedokładności obliczeń. W MECZ, przy odpowiednim doborze funkcji kształtu, sprzężenie czasu i przestrzeni jest rzeczą naturalną. Jest to ważny walor MECZ.

\section{Literatura}

[1] Bailey C.D., 1975. A new look at Hamilton's law of varying action, AIAA J.13, 1154-1157.

[2] Fung Y.C., 1965. Fundation of Solid Mechanics, Englewood Cliffs, Prentice-Hall 1969. Wydanie polskie: Podstawy mechaniki ciała stałego, PWN Warszawa.

[3] Gurtin M.E., Sternberg E., 1962. On the linear theory of viscoelasticity, Arch. Rat. Mech. Anal. 11,1, pp. 291-356.

[4] Kączkowski Z., 1975. The method of finite space-time elements in dynamics of structures, J. Techn. Phys. 16,1, pp. 69-84.

[5] Kączkowski Z., 1976. Metoda czasoprzestrzennych elementów skończonych, Arch. Inż. Ląd., 3(22), ss. 365-378.

[6] Kleiber M. (red.), 1995. Mechanika techniczna, tom XI. Komputerowe metody mechaniki ciał stałych, PWN Warszawa.

[7] Lachowicz M., 2015. Numeryczne modelowanie ośrodka lepkosprężystego, Budownictwo ogólne. Zagadnienia konstrukcyjne, materiałowe i cieplnowilgotnościowe $\mathrm{w}$ budownictwie, Bydgoszcz, Wydawnictwa Uczelnianie UTP, 2015, ss. 91-95.

[8] Nowacki W., 1963. Teoria pełzania, Arkady Warszawa.

[9] Podhorecki A., 2005. Podstawy teoretyczne metody elementów czasoprzestrzennych, Wyd. Uczelniane ATR, Bydgoszcz.

[10] Podhorecki A., 1989. Stabilność rozwiązań w metodzie elementów czasoprzestrzennych, Rozp. Inż., 37, ss. 41-51.

\section{MODELLING OF A VISCOELASTIC CONTINUUM WITH THE USE OF SPACE-TIME ELEMENT METHOD}

\section{S u m m a r y}

The article deals with a viscoelastic continuum which is described by integral equationsi (integral model) with the use of relaxation function (tensor relaxation function). A calculation model for analysis of such continuums with the use of time-space elements has been developed. The included calculation example (viscoelastic disc) indicates correctness and effectiveness of this calculation model.

Keywords: viscoelastic continuum, space-time element method, calculation model

Przestano do redakcji: $30.06 .2017 r$.

Przyjęto do druku: 01.09.2017 r. 